REVIEW

\title{
Functional abdominal pain
}

\author{
P J Matthews, Q Aziz
}

Postgrad Med J 2005;81:448-455. doi: 10.1136/pgmj.2004.030577

Functional abdominal pain or functional abdominal pain syndrome (FAPS) is an uncommon functional gut disorder characterised by chronic or recurrent abdominal pain attributed to the gut but poorly related to gut function. It is associated with abnormal illness behaviour and patients show psychological morbidity that is often minimised or denied in an attempt to discover an organic cause for symptoms. Thus the conventional biomedical approach to the management of such patients is unhelpful and a person's symptom experience is more usefully investigated using a biopsychosocial evaluation, which necessarily entails a multidisciplinary system of healthcare provision. Currently the pathophysiology of the disorder is poorly understood but is most likely to involve a dysfunction of central pain mechanisms either in terms of attentional bias, for example, hypervigilance or a failure of central pain modulation/inhibition. Although modern neurophysiological investigation of patients is promising and may provide important insights into the pathophysiology of FAPS, current clinical management relies on an effective physician-patient relationship in which limits on clinical investigation are set and achievable treatment goals tailored to the patient's needs are pursued.

See end of article for authors' affiliations

....................

Correspondence to: Professor Q Aziz, Department of

Gastrointestinal Sciences, Clinical Sciences Building, Hope Hospital, Manchester M6 8HD, UK; Qaziz@fs 1. ho.man.ac.uk

Submitted

16 November 2004

Accepted

24 December 2004
$\mathrm{P}$ ain is a symptom commonly reported by most patients with functional gastrointestinal disorders (FGD) and while abdominal pain is the most common symptom in irritable bowel syndrome (IBS) it is associated with other physiological events such as disordered defecation, which is not the case in functional abdominal pain syndrome (FAPS). Hence while the mechanisms of pain in FAPS and other FGDs including IBS are likely to be similar, these mechanisms may not explain the associated disorders of physiological function. To be concise we have focused on the mechanisms of pain in FAPS but the reader should be reassured that similar mechanisms are relevant for understanding pain in other FGDs.

FAPS is one of the less common functional gastrointestinal (GI) disorders occurring in less than $2 \%$ of respondents in the US householder study of FGDs compared with $9.2 \%$ for IBS. ${ }^{1}$

Despite its relative low prevalence in the community those FAPS patients with refractory symptoms are very likely to be referred to gastroenterology clinics for further (often invasive) investigations, which have to be considered carefully on the basis of both the appropriateness for the person concerned and proper utilisation of healthcare resources.

Diagnostic criteria for FAPS have been defined by the Rome II multiconsensus group and are:

At least six months of:

- Continuous or nearly continuous abdominal pain; and

- No or only occasional relation of pain with physiological events (for example, eating, defecation, or menses); and

- Some loss of daily functioning; and

- The pain is not feigned (for example, malingering); and

- Insufficient criteria for other FGDs that would explain the abdominal pain. ${ }^{2}$

Clearly this classification satisfies the requirement for a uniform study population in clinical and basic research and is not based on any understanding of the mechanisms responsible for symptom generation that remain largely hypothetical.

\section{MECHANISMS OF VISCERAL PAIN PERCEPTION IN HEALTH AND DISEASE}

In subjects with functional gastrointestinal disorders including FAPS, an almost universal finding is that they experience more pain in response to an experimental visceral stimulation than normal subjects. ${ }^{3}$ This is termed visceral hypersensitivity. To explore this concept we need to understand some basic neurophysiological mechanisms involved in the perception of visceral pain; we will therefore summarise the basic concepts currently considered important.

Pain is a multidimensional experience involving not only an appreciation of the location and severity of noxious stimuli but also evokes an emotional response that might be best thought of as the "suffering" component of pain. Different pain pathways and cerebral regions have been implicated with the pain experience.

Normal visceral pain transduction

To begin let us consider the result of a noxious stimulus within the gut lumen. Our conventional

Abbreviations: FAPS, functional abdominal pain syndrome; FGD, functional gastrointestinal disorders; IBS, irritable bowel syndrome; ST, spinothalamic tract; $\mathrm{SI}$, primary somatosensory cortex; SII, secondary

somatosensory cortex; $\mathrm{ACC}$, anterior cingulated cortex; EEG, electroencepholagraph; PET, positron emission tomography; fMRI, functional magnetic resonance imaging; MEG, magnetoencephalography; TCA, tricyclic antidepressant; $\mathrm{Gl}$, gastrointestinal 
understanding is that after activation of peripheral nerve terminal receptors that are sensitive to mechanical, chemical, or inflammatory stimuli (fig 1), the signal is transducted through spinal visceral afferents, which compose $5 \%$ to $10 \%$ of all fibres in the thoracic and lumbar dorsal roots. ${ }^{5}$ These afferents synapse on the dorsal horn of the spinal cord where release of glutamate induces activation of second order spinothalamic neurones via activation of AMPA ( $\alpha$-amino-3hydroxy-5-methyl-4-isoxazoleproprionic acid) and kainite ligand-gated ion channels. ${ }^{6}$ Sensory information is then conducted via the spinothalamic tract (STT), spinoreticular tract, and spinomesencephalic tracts to the brain. The STT terminates in the medial and posterior thalamus and thalamocortical fibres then projects to the primary somatosensory cortex (SI) and for visceral pain predominately to the secondary somatosensory cortex (SII). ${ }^{7}$ This pathway forms the basis of the sensory discriminatory aspect of the pain experience whereas the spinoreticular and spinomesencephalic pathways eventually terminate on the medial thalamus and from thence, third order thalamocortical fibres ascend primarily to the anterior cingulate cortex (ACC) and insula; both areas encode the reflexive, motivational, and affective properties of the stimulus with the insula additionally involved in the integration of sensory and motor activity (fig 2). Recent evidence suggests the dorsal column that is most commonly known as the conduit of fine touch and vibration stimuli also mediates visceral pain. In a functional MRI experiment Al-Chaer et al ${ }^{8}$ have shown that after lesion of the dorsal column at T10 in a primate model of acute visceral pain, brain activation to colorectal distension is greatly attenuated. Interestingly the converse, a lesion in the STT at T10, failed to achieve the same effect. ${ }^{8}{ }^{9}$

As well as the ascending pathways a number of descending inhibitory pathways play a part in the perception of normal visceral sensation. The origin of the pathways is the opioid rich ACC and from here inhibitory signals are conveyed to the periaqueductal grey either directly or via second order neurones from the amygdala. Other midbrain regions where synaptic connections are made include the locus coeruleus and rostral ventral medulla. Third order opioidergic, serotoninergic and second order noradrenergic neurones connect to the dorsal horn neurones where they "gate" or modulate ascending visceral afferent signals.

This is a simplistic description but is adequate in terms of understanding where abnormalities of pain processing can occur and may contribute to functional abdominal pain.

\section{Abnormal visceral pain perception: the role of peripheral and central sensitisation Peripheral sensitisation}

Studies suggest a third of people after an episode of gastroenteritis will develop IBS and that these people are more likely to show increased levels of mucosal lymphocytes on colonic biopsy compared with controls. ${ }^{10}{ }^{11}$ In addition animal studies, which use models of inflammation, for example GI infection with Trichinella spiralis, show that visceral afferent neurones may remain sensitised after the inflammatory insult has elapsed leading to persistent visceral hypersensitivity and intestinal dysmotility. ${ }^{12}$

Modern biological techniques have characterised possible putative receptors on peripheral nerve terminals that encode noxious stimuli and include: sodium channels, for example, SNS1/SNS2; the P2X3 (purinergic) receptor that is sensitive to adenosine triphosphate (ATP); neurokinin receptors, such as NKl; acid sensitive ion channel (ASIC) receptors in particular ASIC 3 and vanilloid receptors, principally TRPVI. ${ }^{13-16}$ In inflammatory conditions these receptors' sensitivity is increased by the release of local inflammatory mediators like the prostaglandin $\mathrm{PGE}_{2}$, bradykinin, neurotrophins, and cytokines, which can induce increased receptor expression or receptor activation by the removal of local inhibitory mechanisms. For example, after inflammation bradykinin induces activation of protein kinase C (PKC), which in turn leads to sodium channel (SNS) and TRPVI sensitisation.

The neurotrophic factor, nerve growth factor (NGF) is absorbed by the peripheral nerve terminal and retrogradely transported to the cell body where it induces increased TRPVI expression, these new receptors are then anterogradely transported to the peripheral terminal. ${ }^{17}$

$\mathrm{PGE}_{2}$ causes increased cyclic adenosine monophosphate (cAMP) expression via $G$ protein coupled stimulation of adenylate cyclase (AC). cAMP may induce sensitisation by modulation of ion channels, increased receptor expression, or further interactions with secondary messengers, for example, $\mathrm{Ca}^{2+18-21}$ (fig 1). Visceral hypersensitivity might therefore be started by an inflammatory event in the gut such as infection or surgery and in susceptible people induce sensitisation of peripheral nerve terminals, known as peripheral sensitisation (PS).

In addition genetic differences in secondary messengers of immune cell activation, for example, G proteins, which are involved in the transduction of signals from about $80 \%$ of all

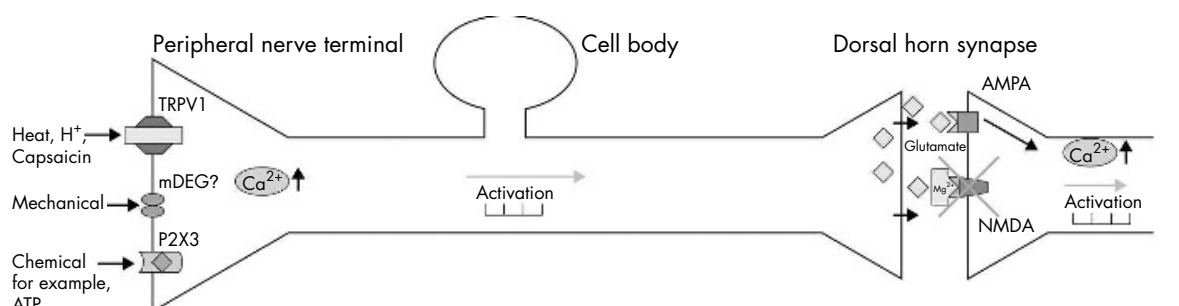

ATP

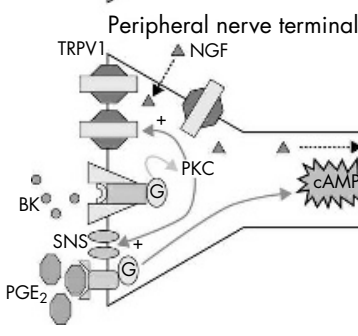

Figure 1 Simplified cartoon showing the major receptor groups and molecular events involved in activation and sensitisation of visceral afferents. (Top) Normal activation. TRPV1, transient receptor potential vanilloid receptor 1 sensitive to $\mathrm{H}^{+}$, noxious heat and capsaicin; $m D E G, m$ Degenerin la candidate receptor for mechanical transduction); $\mathrm{P} 2 \mathrm{X} 3$, purinergic receptor; AMPA, $\alpha$-amino-3-hydroxy5-methyl-4-isoxazoleproprionic acid receptor; NMDA, N-methyl-Daspartate receptor. (Bottom) Sensitisation. At the dorsal horn synapse increased levels of afferent neurone activation lead to the activation of the NMDA receptor by the removal of the magnesium ion block. BK, bradykinin; $\mathrm{PGE}_{2}$, prostaglandin $\mathrm{E}_{2} ; \mathrm{G}$, $G$ protein; PKC, protein kinase C; Src, tyrosine kinase Src. (See text for more details). 


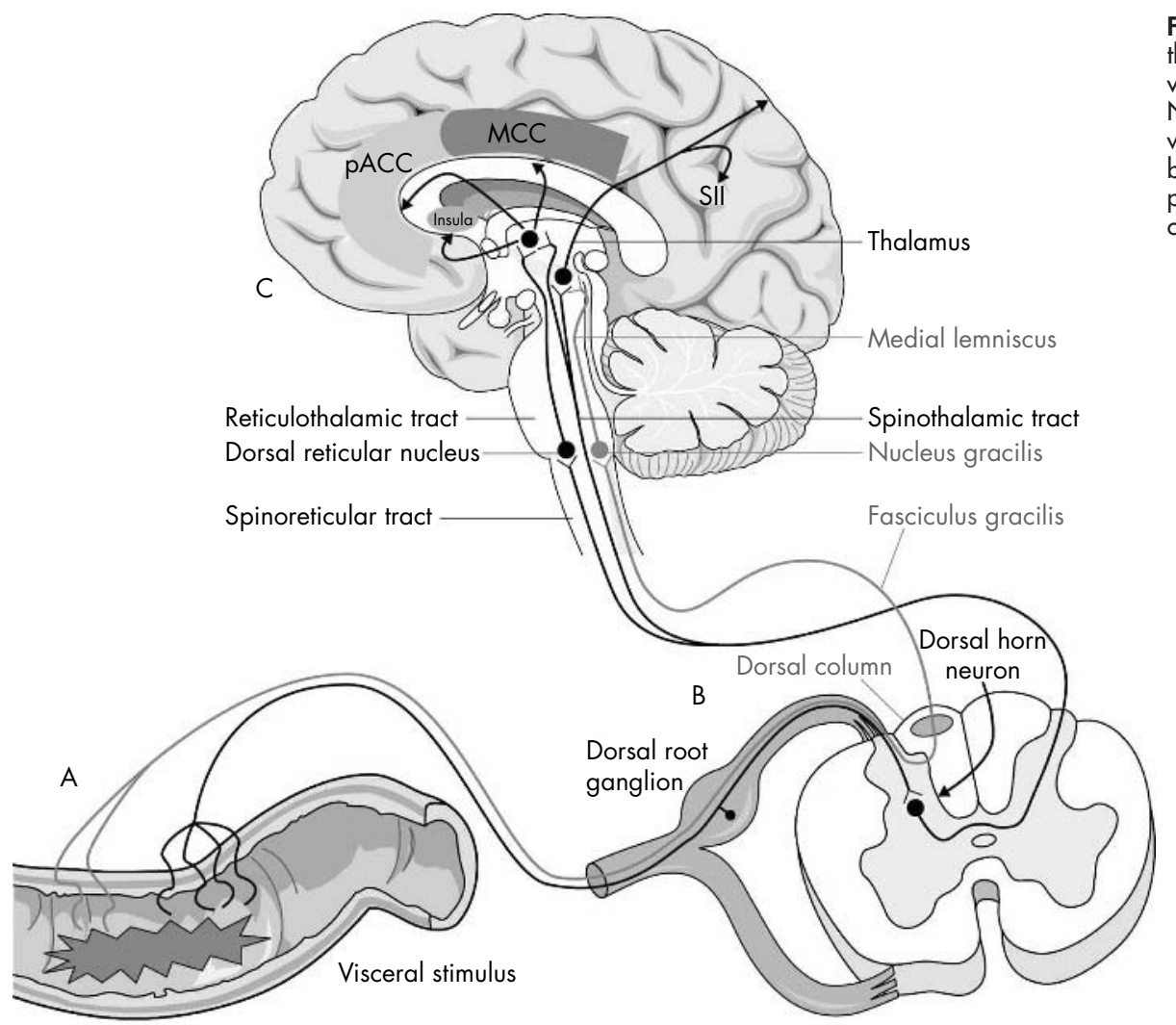

Figure 2 Simplified diagram showing the major pain pathways from the viscera to the central nervous system. Note the inclusion of the dorsal columns whose role in visceral pain perception is becoming increasingly recognised. $\mathrm{pACC}$, perigenual anterior cingulate cortex; MCC, midcingulate cortex.

cellular membrane receptors, may play a part in determining susceptibility to a gut inflammation. G proteins are essential for stimulus-response coupling of receptors linked to intracellular effector systems such as the adenylcyclases, the phosphoinositide system, ion channels, as well as various protein kinases and transcription factors. A recent study has shown that a polymorphism for the gene GNB3 that encodes the 3 subunit of heterotrimeric $G$ proteins may be increased in patients with functional dyspepsia; the authors speculate that the resultant defective $G$ protein signal transduction in these patients may compromise normal immune cell: pathogen interactions in the gut leading to poor pathogen clearance and susceptibility to FGD. Alternatively compromised $G$ coupled signal transduction might also interfere directly with local inhibitory adrenoceptor nerves and induce visceral hypersensitivity. ${ }^{22}$

\section{Central sensitisation}

The increased afferent neurone barrage to the dorsal horn (DH) neurones of the spinal cord because of PS causes central sensitisation (CS) by increased presynaptic glutamate secretion, which leads to the removal of the magnesium ion block of the $N$-methyl-D-aspartate (NMDA) receptor. ${ }^{23}$ Additional key enzymes in the dorsal horn neurone include protein kinase C (PKC) and the tyrosine kinase, Src, which are produced as the end product of the activation of multiple $\mathrm{G}$ protein coupled receptors and further contribute to CS by phosphorylation of the NMDA channel. The resulting increased responsiveness of the dorsal horn neurones outlasts the initiating insult and may only require a low level peripheral input to maintain it. In addition the recruitment of surrounding DH neurones, termed heterosynaptic potentiation, makes the area from which the stimulus originated in the gut appear enlarged (see fig 1).

Recently Willert et al have shown in healthy volunteers that the NMDA antagonist ketamine can reverse acid induced oesophageal hypersensitivity mediated by CS suggesting a role of the NMDA receptor in human visceral hypersensitivity. ${ }^{24}$ Clinical evidence that CS may mediate FAPS comes from studies that show that patients with FGD have an increased likelihood of developing fibromyalgia or to have multiple functional GI syndromes at the same time, or both, for example, functional dyspepsia or non-cardiac chest pain. ${ }^{25} 26$ These clinical findings of a "globally" sensitised somatic and visceral afferent nervous system suggest CS, occurring at the level of the spinal cord is an important mechanism of viscerosomatic and viscerovisceral sensitisation. ${ }^{27} 28$

\section{THE NEUROPHYSIOLOGICAL INVESTIGATION OF VISCERAL PAIN}

Various neurophysiological techniques have been used to explore normal and abnormal pain processing within the central nervous system. Primarily these techniques have focused on the examination of GI afferent pathways and elucidation of the brain areas involved in the cognitive interpretation after a visceral stimulus:

\section{Cortical evoked potentials (CEP)}

In this technique an electroencepholagraph (EEG) is recorded during runs of stimulation (usually electrical or mechanical) of the viscera undergoing investigation. Recording of EEG is phase and time locked with the stimulus and after successive stimuli extraction of background randomly occurring EEG waves can be achieved leaving the desired stimulus evoked brain activity. This technique can be used to assess visceral afferent pathway integrity and may give an indication of whether these pathways have been sensitised to promote visceral afferent transmission to the central nervous system. ${ }^{29-31}$

\section{Positron emission tomography (PET)}

This cerebral scanning technique permits measurement of cerebral blood flow, a proxy of neuronal activity, after the intravenous injection of a radioisotope, for example, labelled 
Table 1 Methods and results of the studies on patients with functional gastrointestinal disorders

\begin{tabular}{|c|c|c|c|c|c|}
\hline Reference & Patients (n) & $\begin{array}{l}\text { Normal subjects } \\
\text { (n) }\end{array}$ & GI tract studied & Technique & Principal findings \\
\hline Furlong et al Neurophysio ${ }^{52}$ & NA & & Oesophagus & MEG & $\begin{array}{l}\text { Non-painful stimulus with balloon distension } \\
\text { caused activation of } \mathrm{SI}, \mathrm{SII} \text {, insular cingulate cortex } \\
\text { and the ACC }\end{array}$ \\
\hline Aziz et al Gastroenterology ${ }^{53}$ & NA & & Distal oesophagus & PET & $\begin{array}{l}\text { Painful and non-painful stimulation. Inferior } \\
\text { border of SI activated with both stimuli. ACC } \\
\text { activation with painful stimuli }\end{array}$ \\
\hline Silverman et al Gastroenterology ${ }^{54}$ & & & Rectum & PET & $\begin{array}{l}\text { Normal subjects: actual or simulated painful } \\
\text { stimuli evoked activation of ACC. IBS subjects left } \\
\text { prefrontal cortex activated but no ACC activation. }\end{array}$ \\
\hline Mertz et al Gastroenterology ${ }^{55}$ & 18 & 16 & Rectum & FMRI & $\begin{array}{l}\text { Normal subjects and IBS showed activation of } \\
\text { thalamus, insular cortex, ACC and prefrontal } \\
\text { cortex. IBS patients reported greater intensity of } \\
\text { pain and had increased ACC activation }\end{array}$ \\
\hline Naliboff et al Gastroenterology ${ }^{56}$ & $\begin{array}{l}42 \text { (IBS) } 23 \\
\text { women } 19 \text { men }\end{array}$ & NA & Rectum & PET & $\begin{array}{l}\text { Female IBS subjects showed greater activation in } \\
\text { the ventromedial prefrontal cortex, right ACC, left } \\
\text { amgdala. Male IBS subjects showed increased } \\
\text { activation in right dorsolateral prefrontal cortex, } \\
\text { insula and PAG. Conclusion: Different sex IBS } \\
\text { subjects differ in activation of brain areas after } \\
\text { visceral stimulation }\end{array}$ \\
\hline Verne et al Pain ${ }^{57}$ & 9 (IBS) & 9 & Rectum & fMRI & $\begin{array}{l}\text { Rectal distension and somatic heat stimulation } \\
\text { compared between IBS and normal controls. } \\
\text { Increased neural processing evoked to both stimuli } \\
\text { in IBS patients and at different cortical levels, } \\
\text { suggesting increased afferent activation, such as, } \\
\text { selective aberrant central nervous processing }\end{array}$ \\
\hline Phillips et $a^{\beta 4}$ & & 8 & Oesophagus & fMRI & $\begin{array}{l}\text { Study in which oesophageal stimuli where } \\
\text { presented with visual stimuli (neutral or fearful } \\
\text { faces). Significantly greater oesophageal } \\
\text { discomfort and activation of left dorsal anterior } \\
\text { cingulated gyri and bilateral anterior insulae } \\
\text { occurred with fearful faces }\end{array}$ \\
\hline
\end{tabular}

water $\left(\mathrm{H}_{2}{ }^{15} \mathrm{O}\right)$ by the detection of positron emitting radionuclides. ${ }^{32}$ Block design experiments are used that compare the perfusion images taken when the subject is at rest with those when the subject is experiencing a visceral stimulus.

\section{Functional magnetic resonance imaging (fMRI)}

fMRI detects increases in blood flow in areas of heightened neuronal activity by the detection of oxygenated haemoglobin. Paradoxically increased neuronal activity and hence blood flow correlates positively with levels of oxyhaemoglobin, as spurts of neuronal activity are associated with anaerobic brain metabolism. Thus increased oxyhaemoglobin at the sites of increased neuronal activity produces an increased signal that can be interpreted to show the structures activated by the visceral stimulus. fMRI has a superior temporal resolution compared with PET of between four and eight seconds and because no radioisotopes are used permits repeated studies on the same subject. ${ }^{33}$

\section{Magnetoencephalography (MEG)}

Visceral stimulation leads to cortical activation that generates minute magnetic fields. These can be detected with highly sensitive sensors known as SQUIDS (super conduction quantum interference device), which are contained within a helmet-like apparatus that covers the subject's head. As well as having comparable spatial resolution to PET and fMRI, MEG has a superior temporal resolution that permits a more dynamic interpretation of brain area activation after visceral stimulation. This latter quality and the technological advances allowing deeper regions of the brain to be studied offer the exciting prospect of providing a second by second evaluation of pain pathway activation and patterns of aberrant pain processing.

The evidence from studies using the above techniques suggests that noxious visceral stimuli produce some differences in cortical activation of the brain than that induced by somatic stimuli. These studies show that cortical processing of visceral sensation entails initial processing in the primary and secondary somatosensory cortices (for sensory discrimination), with subsequent involvement of the anterior cingulate (ACC) and pre-frontal cortices for affect and cognition respectively. This shows that it is possible not only to localise the site of our gut sensation but it is also possible to assign emotional value to it. Furthermore, the study by Phillips $e t a l^{34}$ is of particular relevance to FAPS as it shows that even in normal subjects, visceral stimuli presented within a negative emotional context (that is, oesophageal stimuli presented at a time when subjects were viewing fearful facial expressions on a screen) are rated as more unpleasant and cause significantly more activation of brain areas involved in cognitive pain processing than those stimuli paired with neutral faces. This suggests that the psychological state of the person plays an important part on visceral sensory perception and the brain processing.

Studies have also shown that patients with functional gastrointestinal disorders either display an increased activation in brain areas involved in processing visceral sensation or show different areas of cortical activation than control subjects. However, these studies are preliminary and do not shed light on specific pathophysiological mechanisms of heightened pain perception in patients with functional gastrointestinal disorders. (For a detailed review of the literature on functional brain imaging in functional gastrointestinal disorders please see Hobson and $\mathrm{Aziz}^{35}$ ).

Table 1 describes the results of such studies and the method used in each.

Therefore in summary the mechanisms involved in symptom production in FAPS and other functional digestive disorders are potentially multiple and interconnected. The scientific challenge will be to correctly interpret the results of studies, in the knowledge that no method is without its 
limitations, to produce an organised objective understanding of different phenotypes within this heterogeneous population and from thence to evaluate the potential genetic susceptibilities responsible for them.

\section{CLINICAL EVALUATION OF THE FAPS PATIENT History}

The initial evaluation of FAPS patients in primary and secondary care should be essentially the same and begins when the patient enters the consulting room. A careful history should be taken that takes into account not only the chronology of pain events, for example, relation to surgery or adverse or traumatic life events but attention should be paid to the emphasis and style with that these are described by the patient. Pain is often described by patients in more emotional terms than those with structural disease with terms like "agonising" and "sickening" rather than crampy, sharp, or stabbing. In addition, abdominal pain often covers a large area and may be one of several pains suffered by the patient suggesting concurrent somatisation disorder. The intensity of abdominal pain seldom varies with maximal pain being experienced most of the time, which contrasts with structural disease in which the pain intensity varies and is also more likely to affect other GI activity, for example, motility.

Some behaviour traits may come to light during a consultation that might lend weight to a diagnosis of FAPS. These would include reluctance on the part of the patient to consider the contribution of psychosocial factors to their symptoms and a reliance on invasive investigation to discover an organic cause for the symptoms. Health seeking behaviour is increased in FAPS patients as is the demand for ever increasing analgesia. ${ }^{36}$

Although the above description may be reasonably typical of FAPS patients, it should be emphasised that all patients, whatever the aetiology of their pain are apt to describe their symptoms in more or less dramatic terms and this should be considered in the context of the whole evaluation.

\section{Physical examination}

While characteristically examination in a FAPS patient should fail to discover abnormality, several features should be noted, for example, the absence of autonomic arousal, presence of abdominal scars, and closed eyes sign ${ }^{37}$; in which the subject closes their eyes during examination, which is the

\section{Key points}

- Functional abdominal pain syndrome (FAPS) is one of the functional gastrointestinal disorders (FGD) defined as abdominal pain in the absence of an identifiable disorder.

- FAPS patients are a heterogeneous group whose symptoms are likely to be attributable to multiple causes.

- Disorders of pain processing that include peripheral and central sensitisation, defective descending modulation of afferent pain pathways, and hypervigilance towards normal visceral sensations are likely to be involved in the initiation and maintenance of FAPS.

- Clinical management should include a thorough history including a comprehensive account of psychosocial problems and limited investigations.

- Treatment options include low dose tricyclic antidepressants and psychological approaches, for example, cognitive behavioural therapies. opposite of the more fearful anticipation displayed by sufferers of an acute abdomen.

Distraction can be used with a stethoscope pressing with firm pressure on the abdomen when previously the examining hand may have elicited pain at the same spot. Finally Carnett's test may be performed, in which a painful area is palpated before and after the patient tenses his abdomen by essentially performing a sit up against the resistance of the examiners hand on the subject's forehead. If the subject experiences pain with palpation against tense abdominal musculature, this suggests the cause of the pain is not intraabdominal and may be musculoskeletal in nature. ${ }^{38}$

\section{Investigation}

A limited investigation may be warranted in selected cases and could include screening laboratory studies, for example, full blood count, erythrocyte sedimentation rate, serum biochemistry, and $\mathrm{C}$ reactive protein. In those patients in which alarm features such as rectal bleeding, weight loss, or anorexia are present then another diagnosis should be considered and investigated accordingly. Naturally secondary care providers will feel under pressure to provide endoscopic investigation by both the virtue of ease of access to endoscopy within a district general hospital and the FAPS patient's reliance on such procedures to provide reassurance and explanation to their symptoms. Another cause of worry is the possibility of missing structural disease especially cancer. Several retrospective and prospective studies suggest that diagnostic failures occur in only $0 \%$ to $4.5 \%$ and this should be borne in mind in the follow up of such patients especially if symptoms change. ${ }^{39} 40$

\section{Management}

Several aspects of management are worth clarifying. Patients should be provided with a positive diagnosis of their condition and a full explanation of the diagnosis in an acceptable manner that takes into account their belief system. ${ }^{2}$ This should include a general description that FAPS is a disorder with multiple causes that vary patient to patient, and that the mechanism of symptom generation is not fully understood, but is most probably attributable to a disorder of pain processing and modulation.

It is important to ensure that the patient is aware that an outright cure is unlikely and that the mainstay of treatment is aimed at symptom control. Tricyclic antidepressants (TCA) are widely used in the management of FGDs and are prescribed a low dose, for example, amitriptyline $25 \mathrm{mg}$ once daily. Proposed mechanisms of action include antagonism of the NMDA receptor where they bind and reduce the intracellular accumulation of calcium in spinal neurones and possibly directly via inhibition of $\mathrm{Na}^{+}$and $\mathrm{K}^{+}$channels. ${ }^{41}{ }^{42}$ Low dose TCA are preferred as higher doses lead to sedation and may lead to patient non-compliance and also effective doses are seldom reflected in higher serum concentrations, suggesting that low dose is sufficient for TCA to work as CNS analgesics rather than antidepressants. ${ }^{43}$ Conversely the results of (IBS) studies with selective serotonin reuptake inhibitors (SSRIs) have been conflicting and therefore SSRIs are of uncertain benefit for FAPS patients. ${ }^{43}$ However, some authorities suggest using a dose of fluoxetine $20 \mathrm{mg}$ in isolation or lower doses in combination with TCA in selected patients in whom anxiolysis or control of significant concurrent psychological problems is required. ${ }^{36}{ }^{43-45}$

Narcotic drug treatment is best avoided as opioid gut receptor stimulation eventually leads to opioid receptor down regulation and reduced gut motility-that is, the narcotic bowel syndrome. ${ }^{2}$ 


\section{Key references}

- Drossman DA, et al. eds. Rome II. The functional gastrointestinal disorders. Diagnosis, pathophysiology and treatment: a multinational consensus. 2nd ed. Mclean, VA: Degnon Associates, 2000.

- Mayer EA, Gebhart GF. Basic and clinical aspects of visceral hyperalgesia. Gastroenterology 1994;107: 271-93.

- Woolf CJ, Salter MW. Neuronal plasticity: increasing the gain in pain. Science 2000;288:1765-9.

- Willert RP, Woolfe CJ, Hobson AR, et al. The development and maintenance of human visceral pain hypersensitivity is dependent on the N-methyl-Daspartate receptor. Gastroenterology 2004;126:68392.

- Aziz Q, Thompson DG. Brain-gut axis in health and disease. Gastroenterology 1998;114:559-78.

More resistant cases might benefit from psychological treatments.

\section{Cognitive therapy}

In cognitive therapy, patients are encouraged to explore the maladaptive beliefs about their pain and are encouraged to re-conceptualise their pain and take a more active role in its management. Keeping a diary record with pain sampling taken throughout the day will show the relative variability of symptoms and their association with anxiety or stress that may have accompanied the pain experience. ${ }^{46}$ Therapy is directed at helping the patient to develop an understanding of the interdependent aspects of the pain experience and to use coping strategies that tackle the pain experience in terms of its effect on daily functioning, for example, social, recreational, and financial repercussions. Rather than "curing the pain", treatment goals should be realistic and include short, medium, and long term objectives that help the patient perform their daily activities to their full potential. Available evidence suggests that cognitive therapy is efficacious with almost twice the response rate compared with providing the patient with just information on their disorder. ${ }^{47}$

\section{Behavioural therapies}

Therapy is aimed at increasing activities in a graded way without necessarily involving the self analytical approach detailed above. The emphasis here is on ignoring pain and reinforcing activity related behaviour. Biofeedback has a limited role (if at all) but relaxation and stress management techniques may be useful as part of a behavioural therapy programme. $^{48}$

\section{Hypnosis}

This is perhaps a marginalised area of functional gut disorder research and most of the available evidence pertains to IBS patients. Hypnosis is used to induce general relaxation and also suggestions are made whereby patients are encouraged to use imagery or visualisation in an attempt to assert control over gut sensation/function. Hypnotherapy leads to improved clinical outcomes but also improvements in physiological markers are seen, for example, rectal sensitivity to balloon distension are seen to normalise after hypnotherapy in IBS subjects with reported rectal hypersensitivity. ${ }^{49} 50$

What remains to be seen is the objective effect of hypnosis in the modulation of visceral pain. Recent evidence from an fMRI study of normal subjects hypnotically induced to feel a somatic thermal pain stimulus showed activation within the thalamus, ACC, and insula cortex of greater magnitude than a control group who were requested to recall a previously experienced somatic pain stimulus. This suggests that activation of certain cortical structures can induce pain regardless of peripheral input and may be of great relevance to the cause or continued symptoms experienced by FGD patients. ${ }^{51}$ The results of similar imaging studies with visceral stimuli in normal and patient populations are eagerly awaited.

\section{Summary}

Patients with FAPS form a comparatively small part of the FGD population but present a difficult diagnostic and management problem to the clinician. In contrast with previously held beliefs it is better to consider FAPS in the context of the whole organism by adopting the broader perspective of the biopsychosocial model rather than the more reductionist biomedical model. This requires patience, persistence, and the help of multiple disciplines within primary care and secondary care. Drug treatment options are limited and include TCA and possibly the newer SSRIs but both are probably of little use in more chronic cases without an organised psychological treatment programme.

The elucidation of the mechanisms underlying functional digestive disorders is an exciting area of gastroenterology research and no doubt the solution will be as complex as the problem. FAPS patients represent a heterogeneous group with multiple mechanisms responsible for the initiation and maintenance of symptoms. Therefore the correct identification of these subgroups remains a priority both to clinicians and scientists. Modern imaging and molecular techniques offer the tools for the elucidation of these mechanisms by identification of central nervous system pathways that have undergone sensitisation and modification. Future treatments may entail the activation or attenuation of putative receptors within the GI tract, for example, TRPVI antagonists; spinal cord or brain, for example, NMDA antagonists, which are felt to contribute significantly to symptom production. Furthermore, pharmacogenetics may help to identify those patients with susceptibility to developing FAPS and also those most likely to respond to the above treatments.

\section{MULTIPLE CHOICE QUESTIONS (TRUE (T)/FALSE (F); ANSWERS AT END OF REFERENCES)}

1. True or false

(A) Functional abdominal pain syndrome occurs in about $5 \%$ of the population.

(B) FAPS patients quite often feign symptoms to obtain secondary benefit.

(C) Visceral hypersensitivity may be an important physiological finding in determining the cause of FAPS symptoms.

(D) Visceral pain is transducted in exactly the same pathways as somatic pain.

(E) Central sensitisation can occur at the level of the dorsal horn by the reversal of the magnesium block of the AMPA receptor.

2. Concerning normal visceral pain transduction

(A) Most painful visceral sensations are conducted to the central nervous system via the vagus nerve.

(B) TRPVl receptors are activated by protons or capsaicin and cause a characteristic burning sensation.

(C) Second order spinothalamic neurones are stimulated via activation of AMPA receptors. 
(D) Glutamate is the major excitatory signalling peptide at the dorsal horn synapse.

(E) Serotoninergic and noradrenergic neurones are involved in modulating ascending visceral afferent signals at the level of the dorsal horn.

3. Regarding peripheral sensitisation

(A) A history of gastroenteritis may be reported in up to two thirds of IBS patients

(B) During inflammation NGF release increases TRPVI expression in the neurone cell body.

(C) Increased levels of c AMP may be responsible for afferent neurone sensitisation.

(D) Animal models of GI inflammation often use nematode infections to simulate short lived inflammation.

(E) G protein polymorphisms may be increased in functional gastrointestinal disorders leading to immune cell dysfunction.

4. Regarding functional neuroimaging in FGD studies

(A) PET is an imaging modality that is ideal for repeated scanning of study subjects

(B) MEG has a superior temporal resolution in comparison with fMRI.

(C) Visceral stimuli paired with negative emotional visual stimuli cause greater activation of brain areas involved with processing cognitive aspects of the pain experience.

(D) Increased activation of brain areas on fMRI is analogous with increased levels of oxyhaemoglobin at these sites.

(E) The somatosensory cortices are involved with sensory discrimination of painful stimuli whereas the anterior cingulate and pre-frontal cortices are involved in affect and cognitive processing of visceral pain.

5. Concerning the clinical management of FAPS

(A) A history of previous abdominal surgery may be relevant

(B) Extensive GI investigation is warranted in all cases.

(C) Carnett's test may be useful in discriminating between musculoskeletal pain and visceral pain.

(D) A trial of high dose tricyclic antidepressants should be used in most cases.

(E) Studies of cognitive therapy and hypnosis suggest these therapies are of no benefit in patients with FGDs.

\section{ACKNOWLEDGEMENTS}

The authors thank Mr Nick Trow from the department of medical illustrations, Hope Hospital for his invaluable help with the illustrations.

\section{Authors' affiliations}

P J Matthews, Q Aziz, University of Manchester, Department of Gastrointestinal Sciences, Hope Hospital, Salford, UK

Funding: Professor Aziz's research programme is supported by an MRC career establishment award.

Conflicts of interest: none declared.

\section{REFERENCES}

1 Drossman DA, Li Z, Andruzzi E, et al. US householder survey of functional gastrointestinal disorders. Prevalence, sociodemography, and health impact. Dig Dis Sci 1993;38:1569-80.
2 Drossman DA, Corazziari E, Talley NJ, et al. Rome II. The functional gastrointestinal disorders. Diagnosis, pathophysiology and treatment: a multinational consensus. 2nd ed. McLean, VA: Degnon Associates, 2000

3 Whitehead WE, Engel BT, Schuster MM. Irritable bowel syndrome: physiological and psychological differences between diarrhea-predominant and constipation-predominant patients. Dig Dis Sci 1980;25:404-13

4 Mayer EA, Gebhart GF. Basic and clinical aspects of visceral hyperalgesia. Gastroenterology 1994;107:271-93.

5 Collman PI, Tremblay L, Diamant NE. The distribution of spinal and vagal sensory neurons that innervate the esophagus of the cat. Gastroenterology 1992; 103:817-22.

6 Woolf CJ, Salter MW. Neuronal plasticity: increasing the gain in pain Science 2000;288:1765-9.

7 Aziz Q, Schnitzler A, Enck P. Functional neuroimaging of visceral sensation J Clin Neurophysiol 2000;17:604-12.

8 Willis WD, Al-Chaer ED, Quast ME, et al. A visceral pain pathway in the dorsal column of the spinal cord. Proc Natl Acad Sci U S A 1999:96:7675-9.

9 Al-Chaer ED, Feng Y, Willis WD. A role for the dorsal column in nociceptive visceral input into the thalamus of primates. J Neurophysiol 1998;79:3143-50.

10 Gwee KA, Leong YL, Graham C, et al. The role of psychological and biological factors in postinfective gut dysfunction. Gut 1999;44:400-6.

11 Spiller RC, Jenkins D, Thornley JP, et al. Increased rectal mucosal enteroendocrine cells, T lymphocytes, and increased gut permeability following acute Campylobacter enteritis and in post-dysenteric irritable bowel syndrome. Gut 2000;47:804-11.

12 Bercik P, Wang L, Verdue EF, et al. Visceral hyperalgesia and intestinal dysmotility in a mouse model of postinfective gut dysfunction. Gastroenterology 2004;127:179-87.

13 Yiangou Y, Facer P, Baeker PA, et al. ATP-gated ion channel P2X(3) is increased in human inflammatory bowel disease. Neurogastroenterol Motil 2001;13:365-9.

14 Yiangou $\mathrm{Y}$, Facer $\mathrm{P}$, Dyer $\mathrm{NH}$, et al. Vanilloid receptor 1 immunoreactivity in inflamed human bowel. Lancet 2001;357:1338-9.

15 Yiangou $Y$, et al. Increased acid-sensing ion channel ASIC-3 in inflamed human intestine. Eur J Gastroenterol Hepatol 2001;13:891-6.

16 Holzer P. Gastrointestinal afferents as targets of novel drugs for the treatment of functional bowel disorders and visceral pain. Eur J Pharmacol 2001:429:177-93.

17 Ji RR, Samad TA, Jin SX, et al. p38 MAPK activation by NGF in primary sensory neurons after inflammation increases TRPV1 levels and maintains heat hyperalgesia. Neuron 2002;36:57-68.

18 Chan CL, Facer P, Davis JB, et al. Sensory fibres expressing capsaicin receptor TRPVI in patients with rectal hypersensitivity and faecal urgency. Lancet 2003;361:385-91.

19 Chuang $\mathrm{HH}$, Prescott ED, Kong $\mathrm{H}$, et al. Bradykinin and nerve growth factor release the capsaicin receptor from Ptdlns(4,5)P2-mediated inhibition. Nature 2001;411:957-62

20 Fu LW, Longhurst JC. Interleukin-1 beta sensitizes abdominal visceral afferents of cats to ischaemia and histamine. J Physiol 1999;521:249-60.

21 Collins SM, Piche T, Rampal P. The putative role of inflammation in the irritable bowel syndrome. Gut 2001:49:743-5.

22 Holtmann G, et al. G-protein beta 3 subunit 825 CC genotype is associated with unexplained (functional) dyspepsia. Gastroenterology 2004; 126:971-9.

23 Woolf CJ, Thompson SW. The induction and maintenance of central sensitization is dependent on $\mathrm{N}$-methyl-D-aspartic acid receptor activation; implications for the treatment of post-injury pain hypersensitivity states. Pain 1991;44:293-9.

24 Willert RP, Woolfe CJ, Hobson AR, et al. The development and maintenance of human visceral pain hypersensitivity is dependent on the $\mathrm{N}$-methyl-Daspartate receptor. Gastroenterology 2004; 126:683-92.

25 Whitehead WE, Palsson O, Jones KR. Systematic review of the comorbidity of irritable bowel syndrome with other disorders: what are the causes and implications? Gastroenterology 2002;122:1140-56.

26 Verne GN, Price DD. Irritable bowel syndrome as a common precipitant of central sensitization. Curr Rheumatol Rep 2002;4:322-8.

27 Bernstein CN, Niazi N, Robert M, et al. Rectal afferent function in patients with inflammatory and functional intestinal disorders. Pain 1996;66:151-61.

28 Moriarty KJ, Dawson AM. Functional abdominal pain: further evidence that whole gut is affected. Br Med J (Clin Res Ed) 1982;284:1670-2.

29 Sarkar S, Hobson AR, Furlong PL, et al. Central neural mechanisms mediating human visceral hypersensitivity. Am J Physiol Gastrointest Liver Physiol 2001;281:G1196-202.

30 Hobday DI, Hobson AR, Sarkar S, et al. Cortical processing of human gut sensation: an evoked potential study. Am J Physiol Gastrointest Liver Physiol 2002;283:G335-9.

31 Hobson AR, Willert RP, Matthews PJ, et al. Neurophysiological mechanisms of visceral hypersentivity in non-cardiac chest pain. Gastroenterology 2004; 126(suppl 2):A27

32 Huang SC, Carson RE, Hoffman EJ, et al. Quantitative measurement of local cerebral blood flow in humans by positron computed tomography and 150water. J Cereb Blood Flow Metab 1983:3:141-53.

33 Aziz Q, Thompson DG. Brain-gut axis in health and disease. Gastroenterology 1998;1 14:559-78.

34 Phillips ML, Gregory $\sqcup$, Cullen S, et al. The effect of negative emotional context on neural and behavioural responses to oesophageal stimulation. Brain 2003; 126:669-84.

35 Hobson AR, Aziz Q. Brain imaging and functional gastrointestinal disorders: has it helped our understanding? Gut 2004;53:1198-206. 
36 Drossman DA. Functional abdominal pain syndrome. Clin Gastroenterol Hepatol 2004; 2:353-65.

37 Gray DW, Dixon JM, Collin J. The closed eyes sign: an aid to diagnosing non specific abdominal pain. BMJ 1988;297:837.

38 Carnett J. Intercostal neuralgia as a cause of abdominal pain and tenderness. Surg Gynaecol Obstet 1926;42:625-32.

39 Svendsen JH, Munck LK, Andersen JR. Irritable bowel syndrome-prognosis and diagnostic safety. A 5-year follow-up study. Scand J Gastroenterol 1985;20:415-18.

40 Harvey RF, Mauad EC, Brown AM. Prognosis in the irritable bowel syndrome: a 5-year prospective study. Lancet 1987;i:963-5.

41 Cai Z, McCaslin PP. Amitriptyline, desipramine, cyproheptadine and carbamazepine, in concentrations used therapeutically, reduce kainate- and $\mathrm{N}$-methyl-D-aspartate-induced intracellular $\mathrm{Ca} 2+$ levels in neuronal culture. Eur J Pharmacol 1992;219:53-7.

42 Sawynok J, Esser MJ, Reid AR. Antidepressants as analgesics: an overview of central and peripheral mechanisms of action. J Psychiatry Neurosci 2001;26:21-9.

43 Talley NJ. Pharmacologic therapy for the irritable bowel syndrome. Am J Gastroenterol 2003;98:750-8.

44 Creed F, Fernandes L, Guthrie E, et al. The cost-effectiveness of psychotherapy and paroxetine for severe irritable bowel syndrome. Gastroenterology 2003; 124:303-17.

45 Kuiken SD, Tytgat GN, Boeckxstaens GE. The selective serotonin reuptake inhibitor fluoxetine does not change rectal sensitivity and symptoms in patients with irritable bowel syndrome: a double blind, randomized, placebocontrolled study. Clin Gastroenterol Hepatol 2003;1:219-28.

46 Guthrie E, Thompson D. Abdominal pain and functional gastrointestinal disorders. BMJ 2002;325:701-3.

47 Drossman DA, Toner BB, Whitehead WE, et al. Cognitive-behavioral therapy versus education and desipramine versus placebo for moderate to severe functional bowel disorders. Gastroenterology 2003;125:19-31.
48 Drossman DA. Review article: an integrated approach to the irritable bowel syndrome. Aliment Pharmacol Ther 1999;13(suppl 2):3-14

49 Gonsalkorale WM, Miller V, Afzal A, et al. Long term benefits of hypnotherapy for irritable bowel syndrome. Gut 2003;52:1623-9.

50 Lea R, Hioughton LA, Calvert EL, et al. Gut-focused hypnotherapy normalizes disordered rectal sensitivity in patients with irritable bowel syndrome. Aliment Pharmacol Ther 2003; 17:635-42.

51 Derbyshire SW, Whalley MG, Stenger VA, et al. Cerebral activation during hypnotically induced and imagined pain. Neuroimage 2004;23:392-401.

52 Furlong PL, Aziz Q, Singh KD, et al. Corticol localisation of magnetic fields evoked by oesophageal distension. Electroencephalogr Clin Neurophysiol 1998;108:234-43

53 Aziz Q, Andersson JL, Valind S, et al. Identification of human brain loci processing esophageal sensation using positron emission tomography. Gastroenterology 1997;113:50-9.

54 Silverman DH, Munakata JA, Ennes $\mathrm{H}$, et al. Regional cerebral activity in normal and pathological perception of visceral pain. Gastroenterology 1997; 1 12:64-72.

55 Mertz H, Morgan V, Tanner G, et al. Regional cerebral activation in irritable bowel syndrome and control subjects with painful and nonpainful rectal distention. Gastroenterology 2000;1 18:842-8.

56 Naliboff BD, Berman S, Chang L, et al. Sex-related differences in IBS patients: central processing of visceral stimuli. Gastroenterology 2003;124:1738-47.

57 Verne GN, Himes NC, Robinson ME, et al. Central representation of visceral and cutaneous hypersensitivity in the irritable bowel syndrome. Pain 2003;103:99-110.

\section{ANSWERS}

1. (A) F, (B) F, (C) T, (D) F, (E) F; 2. (A) F, (B) T, (C) T, (D) T,

(E) T; 3. (A) F, (B) T, (C) T, (D) T, (E) T; 4. (A) F, (B) T, (C) T,

(D) T, (E) T; 5. (A) T, (B) F, (C) T, (D) F, (E) F. 